\title{
Photoinduced Production of Chlorine Molecules from Titanium Dioxide Surfaces Containing Chloride
}

\section{$\mathrm{Li}$, Yuanyuan}

2020-02

Li , Y, Nie , W , Liu , Y , Huang , D , Xu , Z, Peng , X, George , C , Yan , C , Tham , Y J , Yu, C, Xia , M , Fu , X, Wang , X, Xue , L, Wang , Z, Xu , Z, Chi , X, Wang , T \& Ding , A 2020 , ' Photoinduced Production of Chlorine Molecules from Titanium Dioxide Surfaces Containing Chloride ' , Environmental Science \& Technology Letters , vol. 7 , no. 2 , pp. 70-75 . https://doi.org/10.1021/acs.estlett.9b00704

http://hdl.handle.net/10138/324441

https://doi.org/10.1021/acs.estlett.9b00704

acceptedVersion

Downloaded from Helda, University of Helsinki institutional repository.

This is an electronic reprint of the original article.

This reprint may differ from the original in pagination and typographic detail.

Please cite the original version. 


\section{Photo-induced Production of Chlorine Molecules from Titanium Dioxide Surfaces Containing Chloride}

Yuanyuan $\mathrm{Li}^{1}$, Wei Nie ${ }^{1}$, Yuliang Liu ${ }^{1}$, Dandan Huang ${ }^{2}$, Zheng $\mathrm{Xu}^{1}$, Xiang Peng ${ }^{3}$, Christian George ${ }^{4}$, Chao Yan ${ }^{5}$, Yee Jun Tham ${ }^{5}$, Chuan $\mathrm{Yu}^{3}$, Men Xia ${ }^{3}, \mathrm{Xiao} \mathrm{Fu}^{3}$, Xinfeng Wang ${ }^{6}$, Likun $\mathrm{Xue}^{6}$, Zhe Wang ${ }^{3}$, Zhengning $\mathrm{Xu}^{1}$, Xuguang Chi ${ }^{1}$, Tao Wang ${ }^{3}$, Aijun Ding, ${ }^{1, *}$

${ }^{1}$ Joint International Research Laboratory of Atmospheric and Earth System Sciences, School of Atmospheric Sciences, Nanjing University, Nanjing, Jiangsu Province, 210023, China

${ }^{2}$ State Environmental Protection Key Laboratory of Cause and Prevention of Urban Air Pollution Complex, Shanghai Academy of Environmental Sciences, Shanghai, 200233, China

${ }^{3}$ Department of Civil and Environmental Engineering, The Hong Kong Polytechnic University, Hong Kong, China

${ }^{4}$ Univ Lyon, Université Claude Bernard Lyon 1, CNRS, IRCELYON, F-69626, Villeurbanne, France

${ }^{5}$ Institute for Atmospheric and Earth System Research / Physics, Faculty of Science, University of Helsinki, P. O. Box 64, 00014, Helsinki, Finland

${ }^{6}$ Environment Research Institute, Shandong University, Jinan, 250100, China

* Correspondence to: Aijun Ding (dingaj@nju.edu.cn)

Abstract: Titanium dioxide $\left(\mathrm{TiO}_{2}\right)$ is extensively used with the process of urbanization, and potentially influence the atmospheric chemistry, yet unclear. In this work, we demonstrated strong production of $\mathrm{Cl}_{2}$ from illuminated $\mathrm{KCl}$-coated $\mathrm{TiO}_{2}$ membrane, and suggest an important daytime source of chlorine radicals. We found that water and oxygen were required for the reactions to proceed and $\mathrm{Cl}_{2}$ production increased linearly with the amount of coated $\mathrm{KCl}$, the humidity of carrier gas and the light intensity. These results suggested that water promotes the reactivity of coated $\mathrm{KCl}$ via the interaction with the crystal lattice to release free chloride ions $\left(\mathrm{Cl}^{-}\right)$. The free $\mathrm{Cl}^{-}$transfer charge to $\mathrm{O}_{2}$ via photoactivated $\mathrm{TiO}_{2}$ to form $\mathrm{Cl}_{2}$ and probably $\mathrm{O}_{2}{ }^{-}$radical. In addition to $\mathrm{Cl}_{2}, \mathrm{ClO}$ 
and $\mathrm{HOCl}$ were also observed via the complex reactions between $\mathrm{Cl} / \mathrm{Cl}_{2}$ and $\mathrm{HO}_{\mathrm{x}}$. An intensive campaign was conducted in Shanghai, during which evident daytime peak of $\mathrm{Cl}_{2}$ was observed. Estimated $\mathrm{Cl}_{2}$ production from $\mathrm{TiO}_{2}$ photocatalysis can be up to 0.2 $\mathrm{ppb} / \mathrm{h}$, which were significantly higher than the photolysis of $\mathrm{ClNO}_{2}$ and highly correlated to the observed $\mathrm{Cl}_{2}$. Our results suggest a non-negligible role of $\mathrm{TiO}_{2}$ in atmospheric photochemistry via altering the radical budget.

\section{INTRODUCTION}

Titanium dioxide $\left(\mathrm{TiO}_{2}\right)$, as the best photocatalyst, has been widely used in environmental remediation ${ }^{1}$ and construction materials ${ }^{2,3}$. The utilization of active $\mathrm{TiO}_{2}$ for self-cleaning ${ }^{4-6}$ or purifying atmospheric pollutants ${ }^{7}$ increased significantly with the process of urbanization in recent years. These $\mathrm{TiO}_{2}$-containing materials, as well as the $\mathrm{TiO}_{2}$-containing particles such as dust $^{8}$ and combustion particles ${ }^{9}$ can play increasing role in the atmospheric chemistry ${ }^{10-13}$. For example, the $\mathrm{TiO}_{2}$ induced heterogeneous photochemical processes can promote the formation of several atmospheric oxidants, including $\mathrm{HONO}^{14,15}, \mathrm{O}_{3}{ }^{11}$, possibly $\mathrm{NO}_{3}{ }^{8,16}$.

Atmospheric $\mathrm{Cl}$ radical, known as produced from the photolysis of $\mathrm{Cl}_{2}$ and nitryl chloride $\left(\mathrm{ClNO}_{2}\right)$, is an important atmospheric oxidant ${ }^{17}$, and influence the ozone and secondary aerosol formation ${ }^{18-20}$. Although concentrations of $\mathrm{Cl}$ radicals are typically lower than those of other atmospheric radicals, they can react with most atmospheric volatile organic compounds (VOCs) faster than hydroxyl radical $(\mathrm{OH})^{21}$ and therefore play an important role in the atmosphere ${ }^{19}$, especially in coastal ${ }^{22}$ and polluted urban areas ${ }^{20,23,24}$. The source of $\mathrm{ClNO}_{2}$ is generated via the heterogeneous reaction of nitrogen pentoxide $\left(\mathrm{N}_{2} \mathrm{O}_{5}\right)$ with particulate chloride ${ }^{25}$. However, there is no consensus on the main sources of $\mathrm{Cl}_{2}{ }^{17,26}$. Although it is traditionally believed that $\mathrm{Cl}_{2}$ should decrease after sunrise due to its fast photolysis, several recent observations have reported evident daytime peaks of $\mathrm{Cl}_{2}$, suggesting a considerable source of lightactivated reactions ${ }^{27-29}$ and possible contribution from photochemical sources. Herein, we report the first direct laboratory observation which confirms that $\mathrm{TiO}_{2}$-mediated 
photocatalytic reactions lead to the production of $\mathrm{Cl}_{2}$, and a few other chlorinated species.

\section{MATERIALS AND METHODS}

Sample preparation. A suspension with $50 \mathrm{ml}$ of $\mathrm{KCl}$ solution and $0.1 \mathrm{~g}$ of $\mathrm{TiO}_{2}$ (Sigma-Aldrich, $21 \mathrm{~nm}$ primary particle size, $\geqslant 99.5 \%$ trace metals basis, product number: 718467) was prepared to homogeneously coat $\mathrm{KCl}$ on $\mathrm{TiO}_{2}$ particles. $\mathrm{The}^{\mathrm{TiO}}{ }_{2}$ particles in the suspension were then filtrated onto a $50 \mathrm{~mm}$ quartz membrane using a water vacuum pump. The membranes were then dried at $323 \mathrm{~K}$ before being used in the experiment. Samples with $\mathrm{KCl} / \mathrm{TiO}_{2}$ mass ratios of $0.0003 \mathrm{~g} / \mathrm{g}, 0.0006 \mathrm{~g} / \mathrm{g}, 0.003 \mathrm{~g} / \mathrm{g}$, $0.0057 \mathrm{~g} / \mathrm{g}, 0.015 \mathrm{~g} / \mathrm{g}, 0.028 \mathrm{~g} / \mathrm{g}$ and $0.06 \mathrm{~g} / \mathrm{g}$ were prepared. The amount of $\mathrm{KCl}$ coated on $\mathrm{TiO}_{2}$ was measured by ion chromatography. A photo of a prepared sample is shown in Fig. S1.

Laboratory experiments. Fig. S2 shows a schematic of the experimental setup of a flow reactor system. The temperature of the system is kept at $293 \mathrm{~K}$. Ultrapure air and nitrogen were used as the carrier gas, which was separated into a dry air flow and a wet air flow. The RH of the inflow to the reactor was adjusted by changing the ratio of dry air to wet air. Four UV lamps were mounted close to the tube, two of which (1 and 2) are used in all the experiments with irradiance of $16.3 \mathrm{~W} / \mathrm{m}^{2}$, except for the experiment testing the role of light intensity. The spectrum of the UV lights is shown in Fig. S3. The irradiance increased from 8.4 to $35.1 \mathrm{~W} / \mathrm{m}^{2}$ from one lamp to four lamps, which covered realistic ranges of solar UVA irradiance during the Shanghai campaign (Fig. S4). The temperature and RH inside the flow tube were monitored continuously. Three instruments, namely, a methyl iodide chemical ionization mass spectrometer (I-CIMS), a $\mathrm{NO}_{x}$ analyzer and an $\mathrm{O}_{3}$ analyzer (Text $\mathrm{S} 1$ ), were used to measure $\mathrm{Cl}_{2}$ and related species in the outflow from the tube. Four experiments were conducted during the lab campaign, and in each of them we varied a single experimental parameter, including coated $\mathrm{KCl}$ amounts, $\mathrm{RH}$ of the carrier gas, light irradiance and carrier gas types.

\section{RESULTS AND DISCUSSION}


Photo-induced production of $\mathbf{C l}_{2}$ from $\mathrm{KCl}$-coated $\mathrm{TiO}_{2}$. The main conclusion of the abovementioned experiments is that significant production of $\mathrm{Cl}_{2}$ occurred in the presence of UV irradiation of a $\mathrm{KCl}$-coated $\mathrm{TiO}_{2}$ membrane. As shown in Fig. 1, we observed a strong production of $\mathrm{Cl}_{2}$, up to $4-5 \mathrm{ppbv}$, from an irradiated sample, of which the $\mathrm{KCl} / \mathrm{TiO}_{2}$ ratio was $0.028 \mathrm{~g} / \mathrm{g}$ and the $\mathrm{RH}$ of the carrier gas was $66 \%$. The decrease in $\mathrm{Cl}_{2}$ concentration indicated fast consumption of the coated $\mathrm{KCl}$. The blank was obtained in many reference experiments, including using a blank membrane, a pure $\mathrm{TiO}_{2}$ sample and a pure $\mathrm{KCl}$ sample, all of which did not show a noticeable increase of $\mathrm{Cl}_{2}$. This confirms that $\mathrm{Cl}_{2}$ was produced from the illuminated $\mathrm{TiO}_{2}$ surfaces containing chloride.

A series of experiments were repeated with varying conditions to investigate the underlying mechanism of $\mathrm{Cl}_{2}$ production and its dependence on potentially relevant parameters. An experiment testing the role of the amount of $\mathrm{KCl}$ coated on $\mathrm{TiO}_{2}$ was carried out under three different $\mathrm{RH}$ values of $9.6 \%, 38 \%$ and $66 \%$, representing very dry to slightly wet environments. The result at $66 \%$, a more atmospherically relevant value, is shown in Fig. 2a. The results at the other RH values are shown in Fig. S5. The observed $\mathrm{Cl}_{2}$ concentration increased linearly as the $\mathrm{KCl} / \mathrm{TiO}_{2}$ ratio increased from $0.0003 \mathrm{~g} / \mathrm{g}$ to $0.0057 \mathrm{~g} / \mathrm{g}$ and reached a plateau thereafter (Fig. 2a). The differences in both the production efficiency and saturated concentrations of $\mathrm{Cl}_{2}$ among $\mathrm{RH}$ values of $9.6 \%, 38 \%$ and $66 \%$ were within the experimental errors, indicating that water is not a limiting factor in atmospherically relevant conditions.

Fig. 3 shows a comparison of $\mathrm{Cl}_{2}$ production among different carrier gases, namely, dry nitrogen gas, wet nitrogen gas $(\mathrm{RH}=38 \%)$, dry air and wet air $(\mathrm{RH}=9.6 \%) . \mathrm{Cl}_{2}$ cannot be observed with nitrogen carrier gas under both dry and wet conditions; instead, it is observed only in the system with wet air as the carrier gas. These results suggest that both water and oxygen are required in the reactions. To further investigate the potential role of water in the reaction, a humidity gradient experiment was conducted by changing the $\mathrm{RH}$ of the carrier gas from $0 \%$ to $88 \%$. Similar to the dependence on the amount of coated $\mathrm{KCl}$, the $\mathrm{Cl}_{2}$ concentration increased linearly with the $\mathrm{RH}$ before 
reaching a plateau (Fig. 2b), indicating that water is either a reagent or a factor influencing the activity of the reagent (chloride).

Free $\mathrm{Cl}^{-}$are believed to be necessary in the reactions to provide electrons to the valence band of photoactivated $\mathrm{TiO}_{2} . \mathrm{KCl}$ can form crystals of $(\mathrm{KCl})_{6}\left(\mathrm{H}_{2} \mathrm{O}\right)_{n}$ with very little water and release free $\mathrm{Cl}^{-}$from the edge of the crystal lattice. This separation could be promoted by the number of water molecules, as solvent-shared ion pairs $\left[\mathrm{K}^{+}\left(\mathrm{H}_{2} \mathrm{O}\right) \mathrm{Cl}^{-}\right]$ are formed with 3-9 water molecules, whereas solvent-separated ion pairs $\left(\mathrm{K}^{+}\right.$and $\left.\mathrm{Cl}^{-}\right)$ can be observed with $10-15$ water molecules ${ }^{30}$. This behavior explains why water can promote the reaction at a value much lower than the deliquescence $\mathrm{RH}$ of $\mathrm{KCl} . \mathrm{Cl}_{2}$ production would be determined by both the intensity of illumination and the amount of free $\mathrm{Cl}^{-}$, which is influenced by both $\mathrm{KCl}$ and water. Under certain light irradiance, $\mathrm{Cl}_{2}$ production will be linearly dependent on the level of free $\mathrm{Cl}^{-}$(either $\mathrm{KCl}$ or water) before reaching a plateau where $\mathrm{Cl}_{2}$ production is saturated and limited by the irradiance (Fig. 2a and 2b).

To test whether the observed plateau for $\mathrm{Cl}_{2}$ production is due to the limitation of light irradiance and the relationship between them, we carried out an experiment in which the light number was adjusted from 4 to 1 . The results showed that the concentration of $\mathrm{Cl}_{2}$ produced linearly correlated with the light number and can reach greater than 10 ppbv (Fig. 2c), suggesting that the observed plateau of $\mathrm{Cl}_{2}$ concentration in both the $\mathrm{RH}$ and coated $\mathrm{KCl}$ experiments is due to the $\mathrm{Cl}^{-}$being saturated under a fixed light irradiance (2 UV lights, $16.3 \mathrm{~W} / \mathrm{m}^{2}$ ).

In addition to $\mathrm{Cl}_{2}$, we also observed the production of $\mathrm{ClO}$ and $\mathrm{HOCl}$ under $66 \% \mathrm{RH}$, which showed similar dependence on the amount of coated $\mathrm{KCl}$ as $\operatorname{did} \mathrm{Cl}_{2}$ (Fig. 2d). The results of 38\% RH are shown in Fig. S5. ClO is another important halogen radical in the atmosphere, while $\mathrm{HOCl}$ can be photolyzed to an $\mathrm{OH}$ radical and a $\mathrm{Cl}$ radical. $\mathrm{ClO}$ is typically believed to be formed via the reaction of $\mathrm{Cl}$ radical and $\mathrm{O}_{3}$ in the atmosphere, which however, was not observed during the experiment, indicating an alternative pathway via the reaction of $\mathrm{Cl}$ radical and $\mathrm{HO}_{2}$ radical to form $\mathrm{ClO}$. Since 
$\mathrm{HO}_{\mathrm{x}}$ has been demonstrated to be produced from the photolysis of water on the surface of $\mathrm{TiO}_{2}{ }^{31-33}$, the reactions of $\mathrm{Cl} / \mathrm{Cl}_{2}$ with $\mathrm{HO}_{\mathrm{x}}$ were thus suspected as the most likely pathway of forming $\mathrm{ClO}$. $\mathrm{HOCl}$ can be produced from either the reaction of $\mathrm{Cl}_{2}$ and $\mathrm{OH}$ or the reaction of $\mathrm{ClO}$ and $\mathrm{HO}_{2}$. Note that $\mathrm{HOCl}$ could react with $\mathrm{Cl}^{-}$ions to reproduce $\mathrm{Cl}_{2}$. However, the concentration of $\mathrm{HClO}$ was too low (more than one order of magnitude) to explain the observed $\mathrm{Cl}_{2}$ concentration.

In summary, we observed strong production of $\mathrm{Cl}_{2}$ and moderate production of $\mathrm{ClO}$ and $\mathrm{HOCl}$ from the photo-induced reaction on $\mathrm{KCl}$-coated $\mathrm{TiO}_{2}$. A mechanism is proposed as the follows. Water reacts with $\mathrm{KCl}$ to release free $\mathrm{Cl}^{-}$, which act as the donor to provide the electron to $\mathrm{O}_{2}$ via the conduction and valence bands of photoactivated $\mathrm{TiO}_{2}$ and form $\mathrm{Cl}$ radical and $\mathrm{O}_{2}{ }^{-}$radical $^{34}$. Two $\mathrm{Cl}$ radicals combine to form the main product, the $\mathrm{Cl}_{2}$ molecule. Water is photolyzed to $\mathrm{OH}$ and $\mathrm{H}^{+}$, which react with $\mathrm{O}_{2}{ }^{-}$immediately to form $\mathrm{HO}_{2}$ radicals. The produced $\mathrm{Cl}_{2}$ further reacts with $\mathrm{OH}$ radical to form $\mathrm{HOCl}$. $\mathrm{Cl}$ radical reacts with $\mathrm{HO}_{2}$ to produce $\mathrm{ClO}$ radical. Most of the products from this reaction pathway are important atmospheric oxidants (or precursors of oxidants) and thus have the potential to influence atmospheric chemistry.

$$
\mathrm{TiO}_{2}+\mathrm{hv} \rightarrow \mathrm{h}^{+}+\mathrm{e}^{-}
$$$$
\mathrm{Cl}^{-}+\mathrm{h}^{+} \rightarrow \mathrm{Cl}
$$

$$
\mathrm{H}_{2} \mathrm{O}+\mathrm{h}^{+} \rightarrow \mathrm{OH} \cdot+\mathrm{H}^{+}
$$

$$
\mathrm{O}_{2}+\mathrm{e}^{-} \rightarrow \mathrm{O}_{2}^{-}
$$$$
\mathrm{O}_{2}{ }^{-} \cdot+\mathrm{h}^{+} \rightarrow \mathrm{HO}_{2} \text {. }
$$

$$
\mathrm{Cl} \cdot+\mathrm{Cl} \cdot \rightarrow \mathrm{Cl}_{2}
$$

$$
\mathrm{Cl}_{2}+\mathrm{hv} \rightarrow \mathrm{Cl} \cdot+\mathrm{Cl} \cdot
$$

$\mathrm{Cl} \cdot+\mathrm{HO}_{2} \cdot \leftrightarrow \mathrm{ClO} \cdot+\mathrm{OH} \cdot$

$$
\mathrm{Cl}_{2}+\mathrm{OH} \cdot \rightarrow \mathrm{HOCl}+\mathrm{Cl}
$$$$
\mathrm{ClO}+\mathrm{HO}_{2} \cdot \mathrm{HOCl}+\mathrm{O}_{2}
$$

$$
\mathrm{HOCl}+\mathrm{hv} \rightarrow \mathrm{Cl} \cdot+\mathrm{OH}^{\cdot}
$$

Atmospheric Implication. In this study, we demonstrated a photo-induced reaction that can produce $\mathrm{Cl}_{2}$ and in turn influence the atmospheric oxidative capacity by 
170 forming $\mathrm{Cl}$ radical and $\mathrm{ClO}$ radical. The role of these reactions in the real atmosphere

171 depends primarily on whether there are considerable amounts of chloride-coated $\mathrm{TiO}_{2}$ materials exposed to the atmosphere. With the process of modern urbanization, $\mathrm{TiO}_{2}$ containing materials have been widely applied for building exteriors ${ }^{35}$ (Fig. S7), selfcleaning glasses, road lamps, airport roofs, and road bricks ${ }^{31}$, and easily be exposure to the urban atmosphere. To further identify the role of the above mentioned reactions in the atmosphere, we tested some commercial $\mathrm{TiO}_{2}$-containing materials, including anatase type $\mathrm{TiO}_{2}$, rutile type $\mathrm{TiO}_{2}$, self-cleaning glass, photocatalytic spray and white pigment. Most of these materials except rutile type $\mathrm{TiO}_{2}$ can produce $\mathrm{Cl}_{2}$ with different efficiency (Fig. S8).

In an area like East China where had elevated concentration of atmospheric chloride ${ }^{36}$ (Fig. S9) and increased application of $\mathrm{TiO}_{2}$ photocatalytic materials ${ }^{29}$, the chloride chemistry involving $\mathrm{TiO}_{2}$ may play an important role in the atmospheric chemistry. We conducted a field campaign in the city center of Shanghai, the largest city in China (Fig. 4), to measure the reactive chlorine compounds, including $\mathrm{Cl}_{2}$ and $\mathrm{ClNO}_{2}$ using an IToF-CIMS, and $\mathrm{HCl}$ and $\mathrm{Cl}^{-}$using an online IC system (MARGA). $\mathrm{Cl}_{2}$ revealed an evident daytime peak, which cannot be explained by the photolysis of $\mathrm{ClNO}_{2}$ and indicate a missing ubiquitous daytime source of $\mathrm{Cl}_{2}$. We calculated the production of $\mathrm{Cl}_{2}$ from $\mathrm{TiO}_{2}$ involving reactions with the assumption of $0 \%-20 \%$ of the land surfaces covered by $\mathrm{TiO}_{2}$-containing materials in urban Shanghai. Estimated $\mathrm{Cl}_{2}$ production rate from $\mathrm{TiO}_{2}$ photocatalysis can be up to $0.2 \mathrm{ppb} / \mathrm{h}$ (see Text S3), which were significantly higher than the photolysis of $\mathrm{ClNO}_{2}$ and highly correlated to the observed $\mathrm{Cl}_{2}\left(\mathrm{R}^{2}=0.97\right)$. These results confirmed an important role of $\mathrm{TiO}_{2}$ involved chlorine chemistry in the atmosphere. However, we can't ensure that this uncertainty range, and need some more statistic collection work get more details about urban usage of $\mathrm{TiO}_{2}$. With the establishment of emerging cities and the use of photocatalytic environmentally friendly materials, this factor may be even higher in the future. 


\section{ASSOCIATED CONTENT}

\section{Supporting Information}

A photo showing the prepared sample of $\mathrm{KCl}$ coated $\mathrm{TiO}_{2}$ (Figure $\mathrm{S} 1$ ). The schematic of the experimental setup of a flow reactor system (Figure S2). Light spectra of the UV lamb (Figure S3). Diurnal variation of UVA during the Shanghai campaign (Figure S4). Dependence of the $\mathrm{Cl}_{2}$ concentration as a function of the amount of coated $\mathrm{KCl}$ with the RH of carrier gas at (a) 9.6\%, and (b) 38\% (Figure S5a and b); (c) Dependence of the $\mathrm{ClO}$ and $\mathrm{HOCl}$ as a function of the amount of coated $\mathrm{KCl}$ with the $\mathrm{RH}$ of carrier gas at 38\% (Figure S5c). Location of the measurement site (Figure S6). Use of exterior wall coatings, production of building coatings and completed construction area from 2000 to 2017 in China (Figure S7). Experiments of some commercial materials containing $\mathrm{TiO}_{2}$ with a carrier gas of pure air of $66 \% \mathrm{RH}$ and $\mathrm{KCl}$ concentration of 0.01 mol/L (Figure S8). Emission map of chlorine ( $\mathrm{HCl}$ and particulate chloride) in East China (Figure S9).

\section{ACKNOWLEDGMENTS}

This work was mainly funded by the National Natural Science Foundation of China (NSFC) project (D0512/41675145 and D0510/91644218) and the National Key R\&D Program of China (2016YFC0200500 and 2016YFC0202000). Data analysis was also supported by other NSFC projects (D0512/41875175 and D0510/41605098). The HK PolyU team was supported by the National Natural Science Foundation of China (91544213) and the Hong Kong Research Grants Council (A-PolyU502/16). Thanks to Min Zhou of the Shang Hai Academy of Environmental Sciences for providing MARGA data during the campaign. 


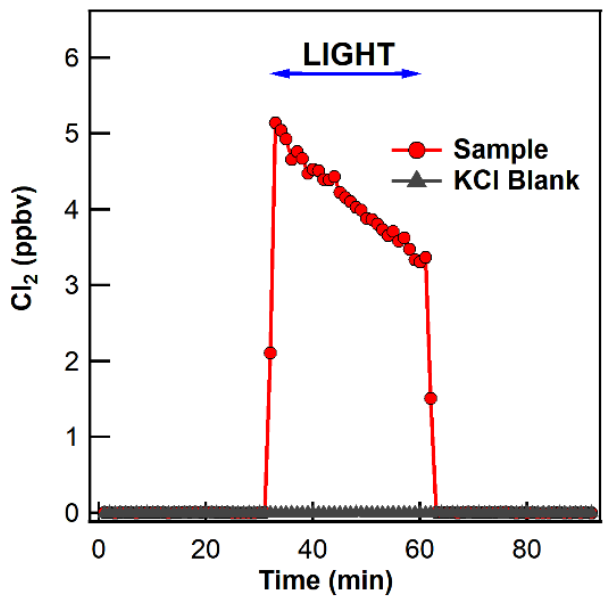

221

222 Figure 1 Effect of light (2 near-UV-emitting lamps in the 350-400 nm wavelength range) on a $\mathrm{KCl} / \mathrm{TiO}_{2}(0.028 \mathrm{~g} / \mathrm{g})$ membrane using ultrapure air. The same blank signal was

224 given by a tube with a $\mathrm{KNO}_{3}$-coated membrane. 

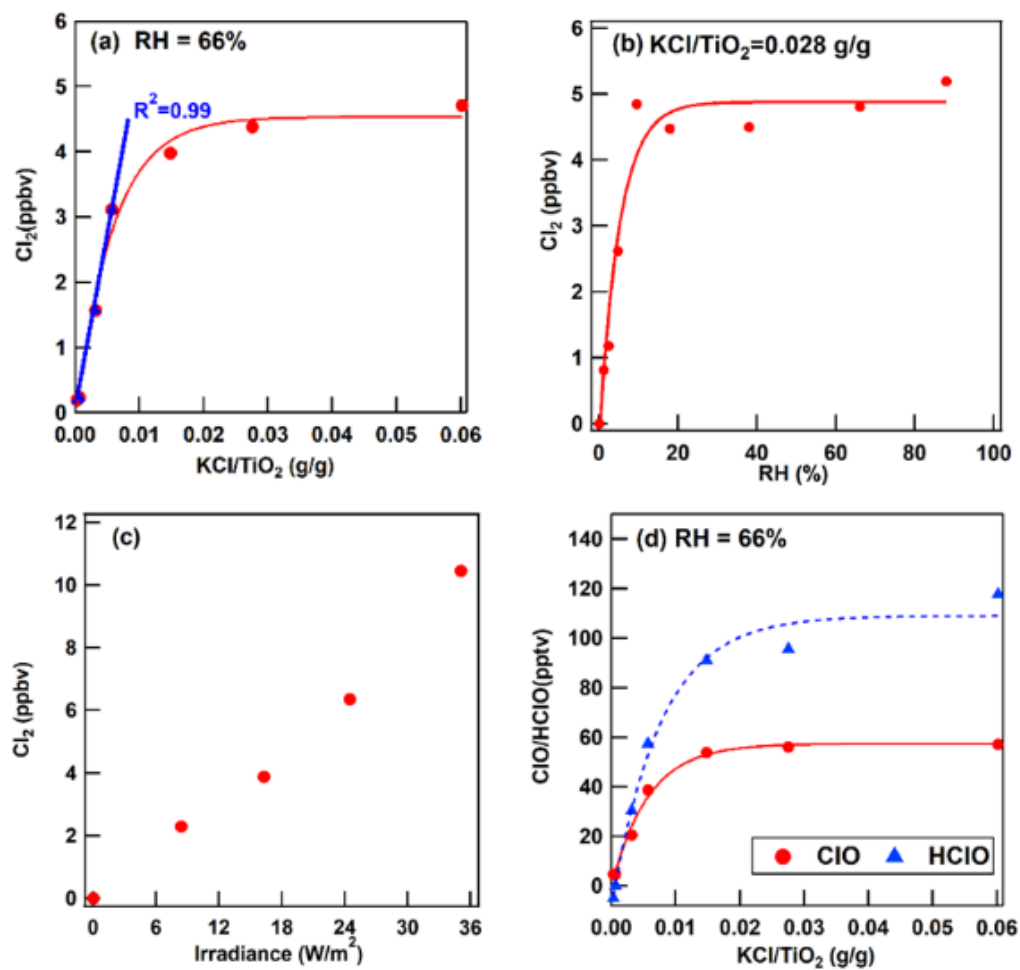

226 Figure 2 Dependence of the $\mathrm{Cl}_{2}$ concentration as a function of (a) the amount of coated $227 \mathrm{KCl}$, (b) the $\mathrm{RH}$ of the carrier gas, and (c) the light irradiance. (d) dependence of the $\mathrm{ClO}$ and $\mathrm{HClO}$ concentration as a function of the amount of coated $\mathrm{KCl}$. The $\mathrm{RH}$ of the carrier gas was $66 \%$ in experiment (a) and (d); a sample with $\mathrm{KCl} / \mathrm{TiO}_{2}=0.028 \mathrm{~g} / \mathrm{g}$ was used in experiment (b); and the light irradiance is represented by the number of lights in experiment (c). Red circle are all data points; red line is the fitting curve; blue triangle are the first four data points, and blue line is a linear fit of these first 4 data points. 


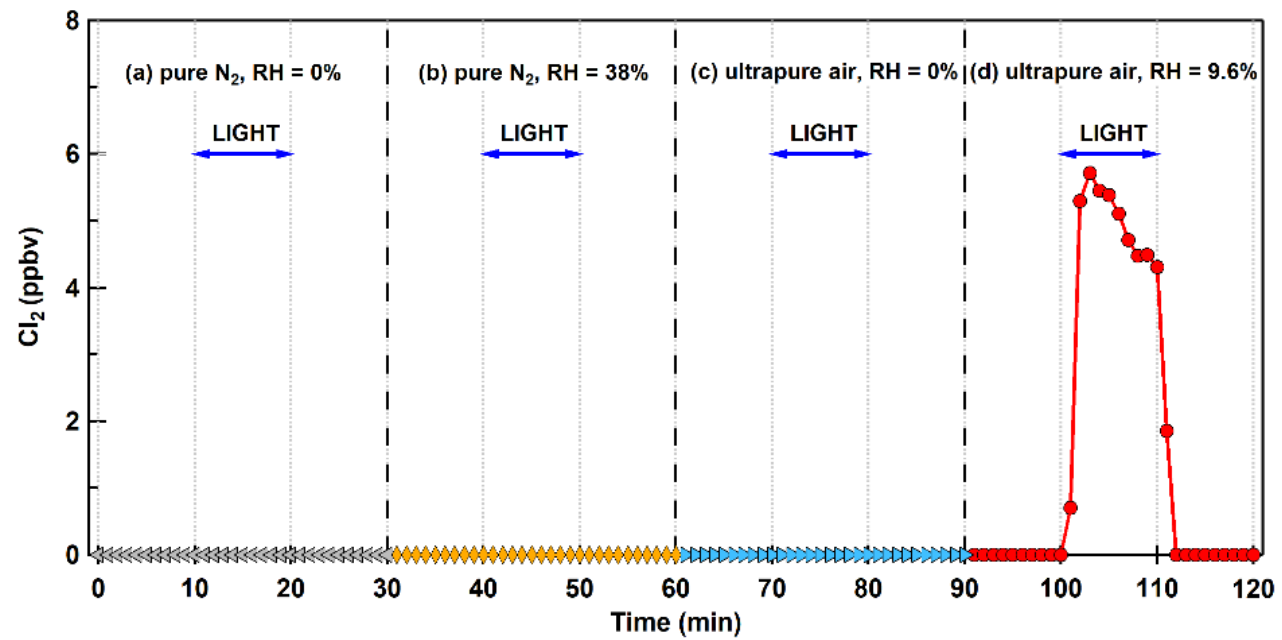

234 Figure 3 Effect of light (2 near-UV-emitting lamps in the 350-400 nm wavelength range) 235 on a $\mathrm{KCl} / \mathrm{TiO}_{2}(0.028 \mathrm{~g} / \mathrm{g})$ membrane with a carrier gas of (a) pure nitrogen with an $\mathrm{RH}$ 236 of $0 \%$, (b) pure nitrogen with an $\mathrm{RH}$ of $38 \%$, (c) ultrapure air with an $\mathrm{RH}$ of $0 \%$, and 237 (d) ultrapure air with an RH of 9.6\%. 

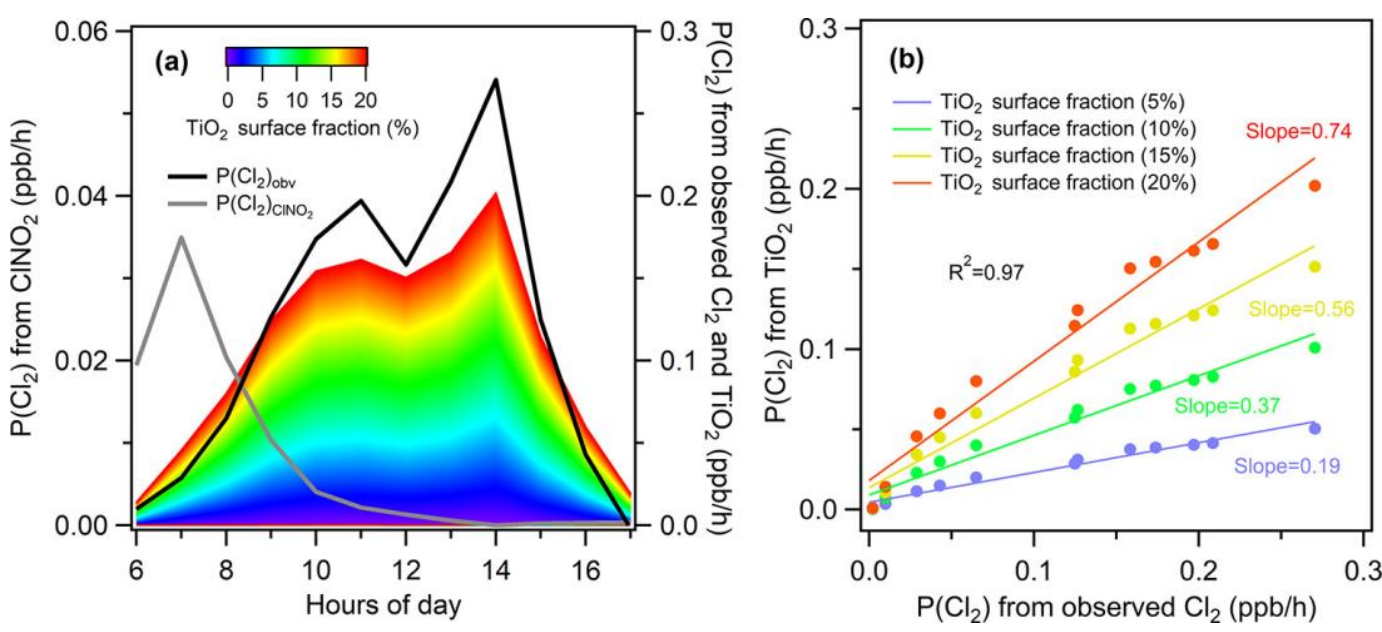

239 Figure 4. (a)Diurnal variations of $\mathrm{Cl}_{2}$ production rate from photolysis of $\mathrm{ClNO}_{2}$, the $240 \mathrm{TiO}_{2}$ involved processes, as well as ambient $\mathrm{Cl}_{2}$ diurnal variation. Filled area represents 241 a range of $\mathrm{Cl}_{2}$ from $\mathrm{TiO}_{2}$ photocatalysis with the assumption of $0 \%-20 \%$ of the land 242 surfaces covered by $\mathrm{TiO}_{2}$-containing materials in urban Shanghai. (b)The correlation 243 between $\mathrm{Cl}_{2}$ production rate from $\mathrm{Cl}_{2}$ observed data and that from $\mathrm{TiO}_{2}$ involved 244 processes when the cover factor is $5 \%, 10 \%, 15 \%$ and $20 \%$ respectively. 

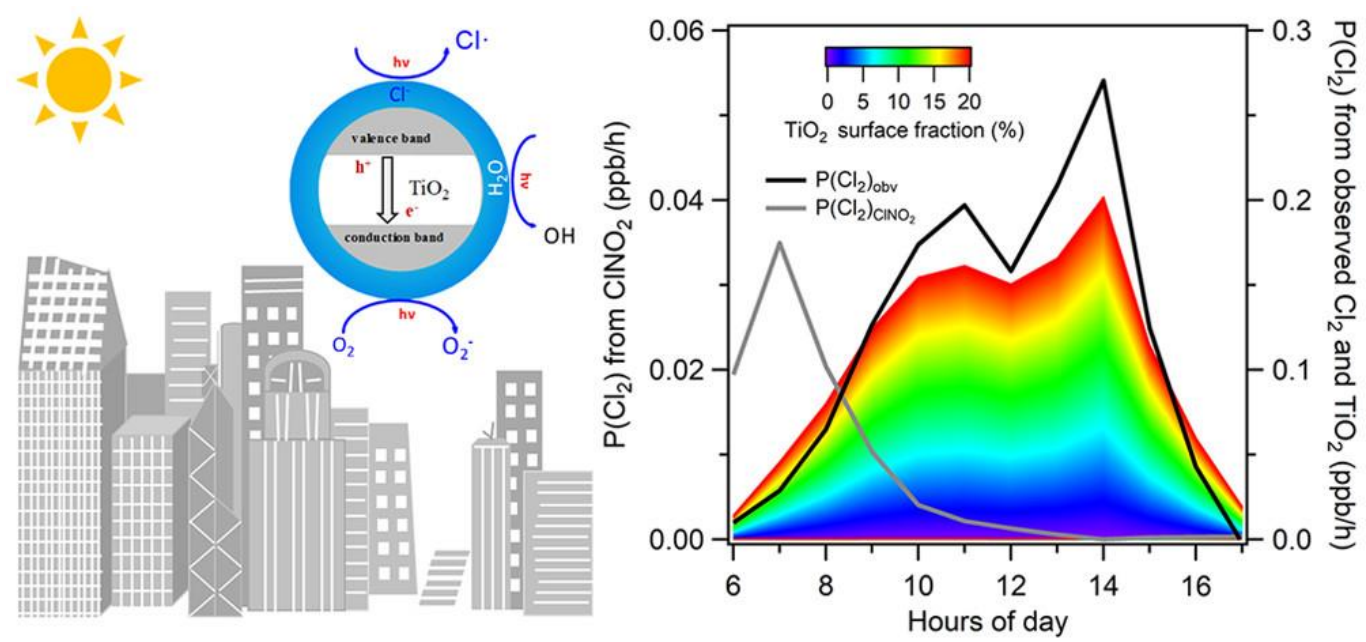

For Table of Contents Only (Abstract Graphic) 


\section{REFERENCES}

1. Mills, A.; Davies, R. H.; Worsley, D., Water-purification by semiconductor photocatalysis. Chemical Society Reviews 1993, 22, (6), 417-425.

2. Guo, M. Z.; Li, J. S.; Poon, C. S., Improved photocatalytic nitrogen oxides removal using recycled glass-nano- $\mathrm{TiO}_{2}$ composites with $\mathrm{NaOH}$ pre-treatment. Journal of Cleaner Production 2019, 209, 1095-1104.

3. Langridge, J. M.; Gustafsson, R. J.; Griffiths, P. T.; Cox, R. A.; Lambert, R. M.; Jones, R. L., Solar driven nitrous acid formation on building material surfaces containing titanium dioxide: A concern for air quality in urban areas? Atmospheric Environment 2009, 43, (32), 5128-5131.

4. Sun, D.; Yu, Y.; Du, G. Aqueous paint useful for purifying atmospheric pollutants, comprises titanium dioxide sol, anti-static component, silica sol, surfactant, dispersant, coalescing agent and water. CN109370269-A, CN109370269-A 22 Feb 2019 C09D-001/00 201929 Pages: 6 Chinese.

5. Zhang, X. T.; Sato, O.; Taguchi, M.; Einaga, Y.; Murakami, T.; Fujishima, A., Self-cleaning particle coating with antireflection properties. Chemistry of Materials 2005, 17, (3), 696-700.

6. Zhu, H. Self-cleaning ceramic paint preparation involves taking ceramic pieces washed in water, placing in muffle furnace, removing and cooling, and then crushing into ultrafine mill to obtain powder, where obtained powder is added into container. CN107216701-A, CN107216701-A 29 Sep 2017 C09D-004/06 201781 Pages: 6 Chinese.

7. Feng, Z.; Han, Y. Building outside wall with high property composite thin film, has wall main portion whose surface is provided with inorganic protection layer that is planted with titanium dioxide composite function layer at surface. CN204081331-U, CN204081331-U 07 Jan 2015 E04F-013/07 201519 Pages: 6 Chinese.

8. Nie, W.; Wang, T.; Xue, L. K.; Ding, A. J.; Wang, X. F.; Gao, X. M.; Xu, Z.; Yu, Y. C.; Yuan, C.; Zhou, Z. S., et al., Asian dust storm observed at a rural mountain site in southern China: chemical evolution and heterogeneous photochemistry. Atmos. Chem. Phys. 2012, 12, (24), 11985-11995.

9. Febrero, L.; Granada, E.; Regueiro, A.; Miguez, J. L., Influence of combustion parameters on fouling composition after wood pellet burning in a lab-scale low-power boiler. Energies 2015, 8, (9), 9794-9816.

10. George, C.; Ammann, M.; D'Anna, B.; Donaldson, D. J.; Nizkorodov, S. A., Heterogeneous photochemistry in the atmosphere. Chemical Reviews 2015, 115, (10), 42184258.

11. Monge, M. E.; George, C.; D'Anna, B.; Doussin, J. F.; Jammoul, A.; Wang, J.; Eyglunent, G.; Solignac, G.; Daele, V.; Mellouki, A., Ozone formation from illuminated titanium dioxide surfaces. Journal of the American Chemical Society 2010, 132, (24), 8234-+.

12. Ndour, M.; Conchon, P.; D'Anna, B.; Ka, O.; George, C., Photochemistry of mineral dust surface as a potential atmospheric renoxification process. Geophysical Research Letters 2009, 36,4 .

13. Nie, W.; Ding, A. J.; Wang, T.; Kerminen, V. M.; George, C.; Xue, L. K.; Wang, W. X.; Zhang, Q. Z.; Petaja, T.; Qi, X. M., et al., Polluted dust promotes new particle formation and growth. Scientific Reports 2014, 4, 6.

14. Gustafsson, R. J.; Orlov, A.; Griffiths, P. T.; Cox, R. A.; Lambert, R. M., Reduction of $\mathrm{NO}_{2}$ 
to nitrous acid on illuminated titanium dioxide aerosol surfaces: implications for photocatalysis and atmospheric chemistry. Chemical Communications 2006, (37), 3936-3938.

15. Ndour, M.; D'Anna, B.; George, C.; Ka, O.; Balkanski, Y.; Kleffmann, J.; Stemmler, K.; Ammann, M., Photoenhanced uptake of $\mathrm{NO}_{2}$ on mineral dust: Laboratory experiments and model simulations. Geophysical Research Letters 2008, 35, (5), 5.

16. Styler, S. A.; Donaldson, D. J., Photooxidation of atmospheric alcohols on laboratory proxies for mineral dust. Environ. Sci. Technol. 2011, 45, (23), 10004-10012.

17. Simpson, W. R.; Brown, S. S.; Saiz-Lopez, A.; Thornton, J. A.; von Glasow, R., Tropospheric halogen chemistry: Sources, cycling, and impacts. Chemical Reviews 2015, 115, (10), 4035-4062.

18. Li, Q. Y.; Zhang, L.; Wang, T.; Wang, Z.; Fu, X.; Zhang, Q., "New" reactive nitrogen chemistry reshapes the relationship of ozone to its precursors. Environ. Sci. Technol. 2018, 52, (5), 2810-2818.

19. Wang, D. S.; Ruiz, L. H., Chlorine-initiated oxidation of n-alkanes under high-NOx conditions: insights into secondary organic aerosol composition and volatility using a FIGAERO-CIMS. Atmos. Chem. Phys. 2018, 18, (21), 15535-15553.

20. Wang, X.; Jacob, D. J.; Eastham, S. D.; Sulprizio, M. P.; Zhu, L.; Chen, Q. J.; Alexander, B.; Sherwen, T.; Evans, M. J.; Lee, B. H., et al., The role of chlorine in global tropospheric chemistry. Atmos. Chem. Phys. 2019, 19, (6), 3981-4003.

21. Atkinson, R.; Baulch, D. L.; Cox, R. A.; Crowley, J. N.; Hampson, R. F.; Hynes, R. G.; Jenkin, M. E.; Rossi, M. J.; Troe, J., Evaluated kinetic and photochemical data for atmospheric chemistry: Volume II - gas phase reactions of organic species. Atmos. Chem. Phys. 2006, 6, 3625-4055.

22. Spicer, C. W.; Chapman, E. G.; Finlayson-Pitts, B. J.; Plastridge, R. A.; Hubbe, J. M.; Fast, J. D.; Berkowitz, C. M., Unexpectedly high concentrations of molecular chlorine in coastal air. Nature 1998, 394, (6691), 353-356.

23. Faxon, C. B.; Allen, D. T., Chlorine chemistry in urban atmospheres: a review. Environmental Chemistry 2013, 10, (3), 221-233.

24. Wang, T.; Tham, Y. J.; Xue, L. K.; Li, Q. Y.; Zha, Q. Z.; Wang, Z.; Poon, S. C. N.; Dube, W. P.; Blake, D. R.; Louie, P. K. K., et al., Observations of nitryl chloride and modeling its source and effect on ozone in the planetary boundary layer of southern China. Journal of Geophysical Research-Atmospheres 2016, 121, (5), 2476-2489.

25. Finlaysonpitts, B. J.; Ezell, M. J.; Pitts, J. N., Formation of chemically active chlorine compounds by reactions of atmospheric $\mathrm{NaCl}$ particles with gaseous $\mathrm{N}_{2} \mathrm{O}_{5}$ and $\mathrm{ClONO}_{2}$. Nature 1989, 337, (6204), 241-244.

26. Phillips, G. J.; Tang, M. J.; Thieser, J.; Brickwedde, B.; Schuster, G.; Bohn, B.; Lelieveld, J.; Crowley, J. N., Significant concentrations of nitryl chloride observed in rural continental Europe associated with the influence of sea salt chloride and anthropogenic emissions. Geophysical Research Letters 2012, 39, 5.

27. Faxon, C. B.; Bean, J. K.; Hildebrandt Ruiz, L., Inland concentrations of $\mathrm{Cl}_{2}$ and $\mathrm{ClNO}_{2}$ in Southeast Texas suggest chlorine chemistry significantly contributes to atmospheric reactivity. Atmosphere 2015, 6, (10), 1487-1506.

28. Liao, J.; Huey, L. G.; Liu, Z.; Tanner, D. J.; Cantrell, C. A.; Orlando, J. J.; Flocke, F. M.; Shepson, P. B.; Weinheimer, A. J.; Hall, S. R., et al., High levels of molecular chlorine in the 
Arctic atmosphere. Nature Geoscience 2014, 7, (2), 91-94.

29. Liu, X. X.; Qu, H.; Huey, L. G.; Wang, Y. H.; Sjostedt, S.; Zeng, L. M.; Lu, K. D.; Wu, Y. S.; Ho, M.; Shao, M., et al., High levels of daytime molecular chlorine and nitryl chloride at a rural site on the North China Plain. Environ. Sci. Technol. 2017, 51, (17), 9588-9595.

30. Sen, A.; Ganguly, B., A computational study toward understanding the separation of ions of potassium chloride microcrystal in water. Theoretical Chemistry Accounts 2012, 131, (12), 13.

31. Chen, H. H.; Nanayakkara, C. E.; Grassian, V. H., Titanium dioxide photocatalysis in atmospheric chemistry. Chemical Reviews 2012, 112, (11), 5919-5948.

32. Henderson, M. A., A surface science perspective on $\mathrm{TiO}_{2}$ photocatalysis. Surface Science Reports 2011, 66, (6-7), 185-297.

33. Wendt, S.; Schaub, R.; Matthiesen, J.; Vestergaard, E. K.; Wahlstrom, E.; Rasmussen, M. D.; Thostrup, P.; Molina, L. M.; Laegsgaard, E.; Stensgaard, I., et al., Oxygen vacancies on $\mathrm{TiO}_{2}(110)$ and their interaction with $\mathrm{H}_{2} \mathrm{O}$ and $\mathrm{O}_{2}$ : A combined high-resolution STM and DFT study. Surface Science 2005, 598, (1-3), 226-245.

34. Setvin, M.; Hulva, J.; Parkinson, G. S.; Schmid, M.; Diebold, U., Electron transfer between anatase $\mathrm{TiO}_{2}$ and an $\mathrm{O}_{2}$ molecule directly observed by atomic force microscopy. Proceedings of the National Academy of Sciences of the United States of America 2017, 114, (13), E2556E2562.

35. Kaegi, R.; Ulrich, A.; Sinnet, B.; Vonbank, R.; Wichser, A.; Zuleeg, S.; Simmler, H.; Brunner, S.; Vonmont, H.; Burkhardt, M., et al., Synthetic $\mathrm{TiO}_{2}$ nanoparticle emission from exterior facades into the aquatic environment. Environmental Pollution 2008, 156, (2), 233-239. 36. Yang, X.; Wang, T.; Xia, M.; Gao, X. M.; Li, Q. Y.; Zhang, N. W.; Gao, Y.; Lee, S. C.; Wang, X. F.; Xue, L. K., et al., Abundance and origin of fine particulate chloride in continental China. Science of the Total Environment 2018, 624, 1041-1051. 